\title{
TURISMO E GERAÇÃO DE EMPREGOS FORMAIS: UM ESTUDO SOBRE OS MUNICÍPIOS INDUTORES DO TURISMO DO ESTADO DE GOIÁS ${ }^{1}$
}

\author{
TOURISM AND FORMAL JOB CREATION: A STUDY ABOUT THE \\ MUNICIPALITIES INDUCERS OF TOURISM OF THE STATE OF GOIÁS
}

\author{
TOURISME ET LA CREATION D'EMPLOIS FORMELS: UNE ETUDE \\ SUR LES INDUCTEURS MUNICIPALITIES DU TOURISME \\ DE L'ÉTAT DE GOIÁS
}

\author{
Gisélia Lima Carvalho - Instituto Federal de Goiás. Goiânia - Goiás - Brasil \\ glc@ifg.edu.br
}

\begin{abstract}
Resumo
0 presente artigo tem o objetivo de contribuir com o conhecimento do perfil da mão de obra formal ocupada no Turismo do Estado de Goiás. A sua relevância se dá devido à necessidade de melhor dimensionar a importância socioeconômica e avaliar o impacto do setor do turismo no Estado, considerando a geração, o perfil de empregos e as condições de trabalho dos seus empregados. Pretende-se, como recorte geográfico, focalizar os Municípios Indutores do Desenvolvimento do Turismo - MIDTUR (Goiânia, Pirenópolis, Caldas Novas, Alto Paraíso, Cidade de Goiás, Aruanã e Rio Quente) a partir da coleta quantitativa de dados fornecidos pela Relação Anual de Informações Sociais (RAIS), do Ministério do Trabalho e Emprego (M.T.E).

Palavras-chave: turismo, empregos formais, municípios indutores do turismo, Estado de Goiás.
\end{abstract}

\begin{abstract}
This article aims to contribute to the knowledge of the profile of the formal workforce employed in the Tourism of the State of Goiás. Its relevance is due to the need to better scale the socioeconomic importance and also to assess the impact of the Tourism Sector in the state considering the employment generation, its profile and the working conditions of the employees. By using a geographic delimitation, we intend to focus on the municipalities which are inducers of the Development of Tourism - MIDTUR (Goiânia, Pirenópolis, Caldas Novas, Alto Paraíso, Cidade de Goiás, Aruanã and Rio Quente) based on a quantitative collect of data provided by the Relação Anual de Informações Sociais (RAIS) of the Ministério do Trabalho e Emprego (M.T.E.). Key words: tourism, formal jobs, municipalities inducers of tourism, State of Goiás.
\end{abstract}

\section{Résumé}

Cet article vise à contribuer à la connassance du profil de la population active employée dans le tourisme formelle de l'État de Goiás. Sa pertinence est due à la nécessité de mieux dimensionner l'importance socioeconomique et estimer l'impact du secteur de tourisme dans l'état prennent en compte la génération d'emploi, le profil des emplois et des conditions de travail des employés. Comme un coupure géographique, on a l'intention de concentrer la recherche sur les inducteurs du développement du tourisme - MIDTUR (Goiânia, Pirenópolis, Caldas Novas, alto Paraíso, Aruanã et Rio Quente) à partir de la collecte quantitative de données fournies par Relação Anual de Informações Sociais (RAIS) et le Ministério do Trabalho e Emprego (M.T.E.).

Mots clés: tourisme, emplois formels, inducteurs municipalités du tourisme, l'État de Goiás. 
Introdução

O turismo, enquanto atividade socioeconômica, é produtor de impactos capazes de transformar a realidade das localidades. Sendo uma atividade característica do setor de serviços, possui intensivo potencial de geração de emprego e renda, além de implicações na organização geográfica das localidades em que se instala. No Estado de Goiás o turismo não tem sido trabalhado de modo que seus índices permitam visualizar a sua importância socioeconômica e avaliar seus resultados, considerando a criação e o perfil de empregos. Nesse sentido, as ações do setor privado e público podem ser comprometidas, no que diz respeito à definição de metas, diretrizes e estratégias. Levando isso em conta, o presente artigo pretende contribuir com construção de um cenário sobre o perfil dos empregados formais ocupados no Turismo do Estado de Goiás, bem como analisar o seu comportamento no período entre 2000 e 2008. Assim, se propõe a responder as seguintes perguntas: como se apresentam os números do mercado de trabalho formal, em relação à mão de obra do turismo nos Municípios Indutores do Turismo goiano? qual é o perfil dos empregados nas Atividades Características do Turismo nesses municípios?

Para o estudo foram delimitadas as categorias denominadas características do turismo. A Organização Mundial do Turismo (OMT) definiu 189 códigos específicos do turismo. A partir deste mecanismo é possível medir o consumo de bens e serviços vinculados às Atividades Características do Turismo (ACTs), bem como "avaliar o impacto geral desta atividade sobre a economia e sobre o nível de emprego", como destaca Cala (et al., 2006, p. 52). Já o Instituto de Pesquisa Econômica Aplicada (IPEA) utiliza como metodologia em suas pesquisas uma lista generalista de produtos característicos do turismo que serviu de referência para este estudo. Os setores utilizados pelo IPEA, que seguem a Classificação Nacional de Atividades Econômicas (CNAE), são: 1. Alojamento; 2. Alimentação; 3. Agências de viagem; 4. Transporte; 5. Auxiliares do Transporte não reconhecidas como preferentemente turísticas; 6 . Aluguel de veículos e 7 . Cultura e Lazer. Estas são tomadas aqui como Atividades Características do Turismo (ACTs).

$\mathrm{O}$ universo desta pesquisa abrangeu a escala local com enfoque para aqueles municípios goianos em que os resultados das atividades características do turismo tiveram maior destaque nos últimos anos e que hoje são denominados pela a Agência Estadual de Turismo (GOIÁS TU- 
RISMO) como "Municípios Indutores do Desenvolvimento do Turismo (MIDTUR)”. São eles: Goiânia, Pirenópolis, Caldas Novas, Alto Paraíso, Cidade de Goiás, Aruanã e Rio Quente. Já a escala temporal compreendeu o período entre 2000 e 2008. A partir de então, partiu-se para a aquisição de dados sobre emprego formal tendo como fonte a Relação Anual de Informações Sociais (RAIS), do Ministério do Trabalho e Emprego (M.T.E)².

\section{Os municípios Indutores do Turismo no Estado de Goiás}

O Estado de Goiás compõe o mapa dos destinos turísticos resultante do Projeto de Regionalização do turismo no Brasil, do Ministério do Turismo, com os municípios de Alto Paraíso de Goiás, Caldas Novas, Goiânia e Pirenópolis (MTUR/EMBRATUR, 2007). A Goiás Turismo, em seu Plano Estadual do Turismo, acrescentou a aqueles os municípios de Goiás, Aruanã e Rio Quente que, somados, compõem os chamados Municípios Indutores do Desenvolvimento do Turismo do Estado de Goiás (MIDTUR), representados na figura 01.

Rio Quente e Caldas Novas, no sudeste goiano, têm nas águas quentes um atributo turístico bastante explorado e, em consequencia disso, a presença de hotéis e intensa verticalização como uma característica muito refletida na paisagem urbana. Conforme dados do IBGE (2011), esses municípios ainda possuem, proporcionalmente, o maior número de domicílios de uso ocasional ${ }^{3}$. Utilizando-se dos atributos do sítio histórico e dos ecológicos, estão os municípios de Goiás e Pirenópolis. O primeiro com influência de fluxo turístico intenso de Goiânia e o segundo, além da capital estadual, recebe frequente fluxo de Brasília. Alto Paraíso de Goiás, onde se localiza a Chapada dos Veadeiros, tem destaque nacional no roteiro ecológico, fazendo parte da Região da Reserva da Biosfera Goyaz, reconhecida pela UNESCO e que passou, com isso, a ter prioridade em ações de conservação e desenvolvimento sustentável ${ }^{4}$. Aruanã, às margens do Araguaia, tem como principal característica o fluxo turístico intermitente, concentrando a temporada com a baixa do Rio Araguaia. Como pouca infraestrutura voltada para o turismo, este município apresenta baixíssimos índices de emprego registrados no setor (apenas 10, segundo a Rais, 2008). Dos 3.659 domicílios recenseados pelo IBGE (2011) 25\% são de uso ocasional. Já o município de Goiânia, com características bem diferenciadas dos demais, destaca-se como roteiro de turismo pela sua centralidade 
em relação ao país agregando-lhe, com isso, vantagens ao turismo de negócios e eventos.

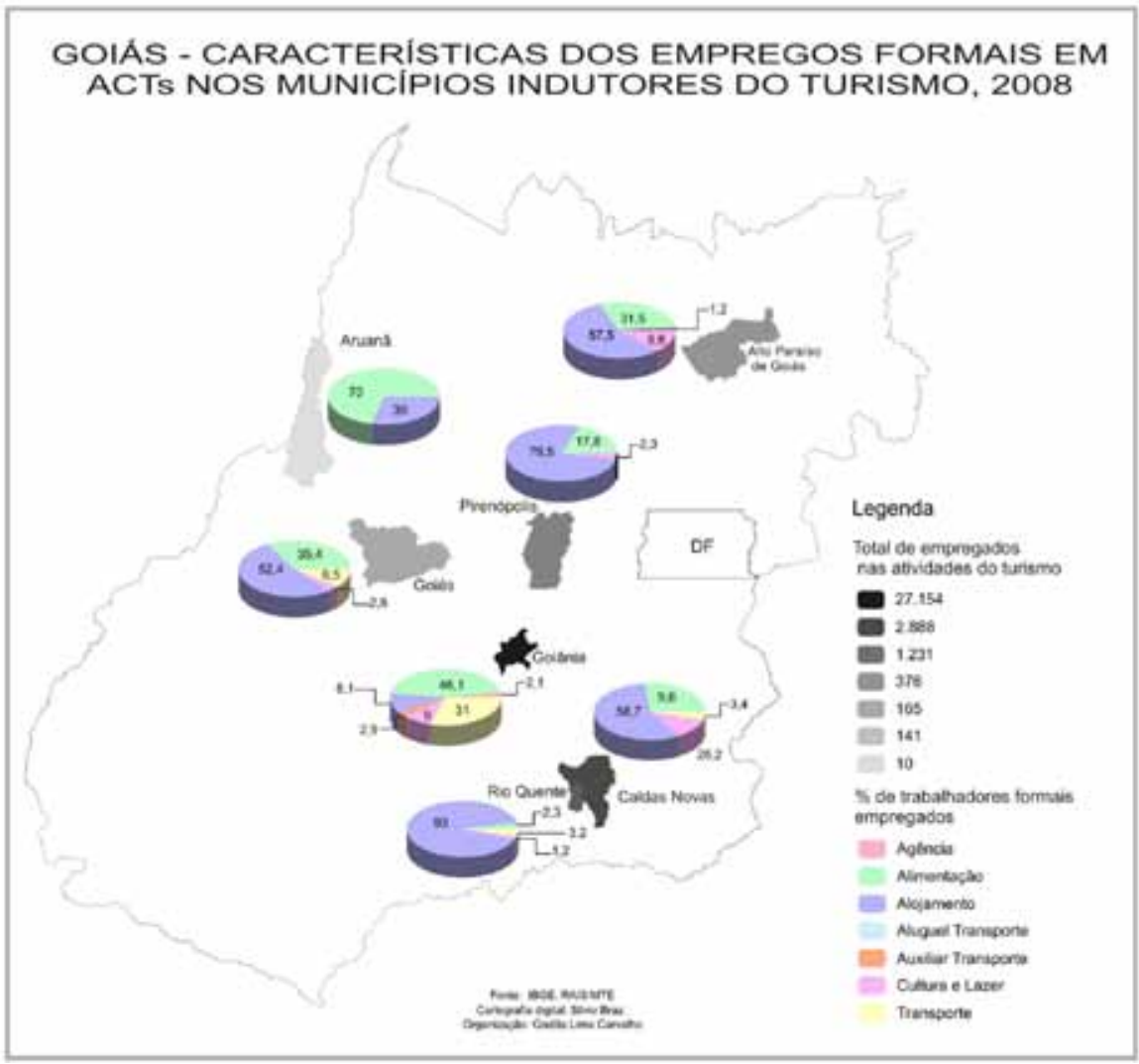

Figura 01

Em comum, o que esses municípios têm é que, de algum modo, refletem em sua espacialidade e economia os impactos causados pela atividade turística. Desses impactos, o objeto aqui é a geração de empregos formais, que se expressa de modo bastante diferenciado em todos os municípios referenciados. Isto significa que há municípios goianos que chegam a ter até mais pessoas ocupadas em atividades características do turismo que nos próprios municípios indutores, uma vez que o que é tido como essencialmente turístico o é também para a dinâmica de toda cida- 
de que necessita de serviços e equipamentos urbanos, ainda que esta não receba um fluxo de turistas. É o caso dos municípios como Aparecida de Goiânia, Anápolis, Itumbiara, Rio Verde, Catalão, entre outros. No entanto, os 7 municípios do MIDTUR representam sozinhos a maior parte dos registros de empregos. Ou seja, em 2000, do total de empregos formais do turismo no estado, 63,63\% advinham destes municípios e em 2008, embora com queda no número, eles ainda detinham 57,78\% do total no setor, segundo a RAIS. Os números de empregados formais nestes municípios, em 2008, foram os seguintes: Goiânia (27.154); Caldas Novas (2.888); Rio Quente (1.231); Pirenópolis (376); Alto Paraíso de Goiás (165); Goiás (141) e Aruanã (10), conforme figura 01.

Para um maior detalhamento de como se dá a segmentação e a proporcionalidade desses dados, por atividade turística e segundo o MIDTUR, segue a abordagem deste artigo a partir da descrição e da análise do perfil dos empregados formais.

\section{0 perfil dos empregados no setor turístico}

Existe uma diferença discrepante entre o número de trabalhadores empregados nas ACTS do Estado de Goiás e o Brasil ${ }^{5}$. O Estado emprega apenas $2,30 \%$ do número de trabalhadores contratados no Brasil. Já a relação entre o número de trabalhadores empregados nas ACTs com as demais atividades econômicas praticadas nos Municípios Indutores do Turismo, revela-nos que, em 2000, esse percentual foi de 5,1\%, subindo para 7,06\%, em 2004, e caindo, significativamente, para 4,64\%, em 2008 (Figura 02).

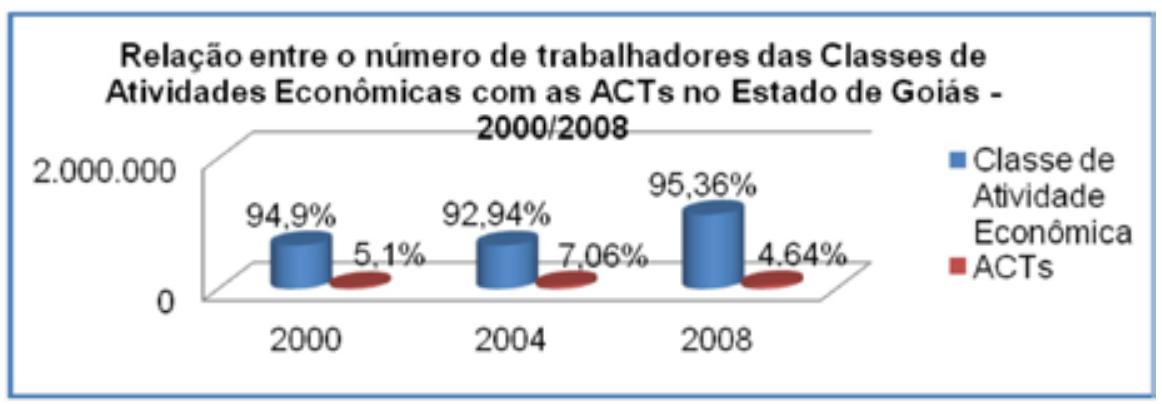

Figura 02

Fonte: RAIS/M.T.E 
Como no Brasil, as ACTs que mais empregaram formalmente no Estado de Goiás foram as de Alimentação, em 2008, com 21.386 mil trabalhadores, seguida das de Transporte, que somaram $19.289 \mathrm{mil}$ ocupações. A atividade de Alojamento cresceu substancialmente no período, saltando de 529 contratações formais, em 2000, para $9.842 \mathrm{mil}$, em 2008. A ACT de cultura e lazer cresceu de 2000 para 2004, mas, em 2008, obteve queda expressiva. De modo geral, as contratações nas ACTs nos Municípios Indutores têm crescido. Em 2000 foram 35.736 mil contratações, em 2004, 50.499 mil e, em 2008, 55.300 mil. Conforme o mapa (Figura 01), o município de Goiânia foi o único que obteve registro de empregados em todas as atividades turísticas, com destaque para o setor de alimentação (46,1\%), seguido do de transporte (31\%), de cultura e lazer (9\%), de alojamento (8,1\%). Os demais setores (auxiliar e aluguel de transportes e agências de viagens) representaram um pouco mais que $5 \%$ dos contratos. Na maioria dos municípios o setor de hospedagem é o mais empregador de todas as ACTs. Em Rio Quente ele representou, em 2008, 93\% dos registros, em Pirenópolis 79,5\%; em Caldas Novas 58,7\%; em Alto Paraíso de Goiás 57,5\%; em Goiás 52,4\% e em Aruanã 30\%. O setor de alimentação é o segundo com mais registros de empregados, sobretudo no último município citado, representando um total de $70 \%$ dos registros. Este setor também se destaca como bom empregador em Goiás (35,4\%) e em Alto Paraíso de Goiás (31,5\%), conforme Figura 01.

\section{Faixa de rendimento médio}

O rendimento médio dos empregados nas ACTs no MIDTUR ainda é baixo, uma vez que $64 \%$ receberam, em 2008, entre 1,01 e 2 Salários Mínimos (sm), seguidos de $28 \%$ que receberam entre 2,01 e $5 \mathrm{sm}$, ocorrendo ainda registros de empregados que receberam até $1 \mathrm{sm}(5 \%)$.

No município de Goiânia observou-se aumento no número de trabalhadores nas faixas menos elevadas, ou seja, entre 1,01 e $2 \mathrm{sm}$ e decaído o número de trabalhadores com rendimentos mais elevados. Na ACT de Agência de Viagens os rendimentos ficaram concentrados na faixa de 1,01 e 1,5 sm, o que, em 2000, correspondia a 38,18\% dos empregados e, em 2008, esse número saltou para $45,51 \%$. Na ACT de Alimentação os rendimentos também se mantiveram nesta faixa, sendo 50,40\%, em 2000, e 62,26\%, em 2008. Na ACT de Alojamento os rendimentos caíram nas 
faixas entre 1,0 1 e 1,5 sm, saindo de 32,66\%, em 2000, e 21,6\%, em 2008, e na faixa entre 1,51 e $2 \mathrm{sm}$, caindo de $41,33 \%$, em 2000, para $26,95 \%$, em 2008. Na ACT de Transporte houve aumento de mão de obra recebendo na faixa entre 2,01 e $3 \mathrm{sm}$ que, em 2000, eram 13,34\% e, em 2008, esse valor saltou para 32,67\%. Destacam-se também os ganhos na faixa de 3,01 e 4 sm que ficou entre os $26 \%$ no período de 2000 a 2008. Na ACT de Cultura e Lazer os rendimentos cresceram, sobretudo, na faixa de rendimento de 1,01 a $1,5 \mathrm{sm}$ saltando de $27,20 \%$, em 2000 e para 50,45\%, em 2008. Alto Paraíso, na ACT de alimentação, as contratações na faixa de 1,01 e 1,5 sm saltaram de 65\%, em 2000, para 76,92\%, em 2008, e na ACT de Alojamento passou de 20\%, em 2000, para 68,42\%, em 2008.

Em Pirenópolis, na ACT de Alimentação, 52,94\% dos trabalhadores tinham rendimentos entre 0,51 e $1,5 \mathrm{sm}$, em 2000 , caindo para $48 \%$, em 2008. Isso se deveu, ao que parece, à queda de salários de empregados, uma vez que a faixa entre 0,5 e $1 \mathrm{sm}$ apresentou aumento no período, passando de $32,35 \%$ para $44 \%$. Na ACT de Alojamento os rendimentos também se concentram na faixa entre 1,01 e 1,5 sm, sendo que em 2000 as contratações correspondiam a 3,57\% e em 2008 elas chegaram a 57,85\%. No município de Caldas Novas os rendimentos médios se concentram nas faixas entre 0,51 e $1 \mathrm{sm}$ até 4,01 e $5 \mathrm{sm}$. Sendo que na ACT de Alimentação os rendimentos entre 1,01 e 1,5 sm corresponderam a 43,5\% dos contratados, em 2000, e 65,78\%, em 2008. Os rendimentos entre 1,51 e $2 \mathrm{sm}$ sofreram pequeno decréscimo, mas sem deixar de representar parte importante dos ganhos: 37,28\%, em 2000, e 23,38\%, em 2008. Na ACT de Alojamento não foi diferente, os rendimentos se concentraram nas faixas entre 1 e 1,5 sm e 1,5 e $2 \mathrm{sm}$, sendo que a primeira faixa correspondeu a $48,57 \%$ dos ganhos, em 2000 , e $55,72 \%$, em 2008 , e a segunda faixa a $20 \%$ dos rendimentos, em 2000, e 22\%, em 2008. O setor de transporte apresentou queda nos pagamentos entre 2,01 e $3 \mathrm{sm}$ e aumentou o número de funcionários recebendo, entre 0,5 e $1 \mathrm{sm}$ entre 1,0 1 e 1,5 sm e entre 2,01 e $3 \mathrm{sm}$. Na ACT de cultura e lazer os rendimentos médios concentraram-se na faixa salarial entre 1,01 e 1,5 sm, em 2000, foram $37,28 \%$ e, em 2008 , esse percentual saltou para $52,87 \%$.

No município de Goiás, em 2008, os rendimentos também ficaram distribuídos nas faixas entre 0,51 e $1 \mathrm{sm}$ para $12 \%$ dos trabalhadores e entre 1,01 e 1,5 sm para a maioria de $57 \%$ e entre 1,51 e $2 \mathrm{sm}$ para $20 \%$, sendo que as atividades que mais empregaram foram as de Alojamento, 
Alimentação e Transporte. Na ACT de Alojamento os ganhos entre 0,51 e $1 \mathrm{sm}$ alcançaram 32,35\%, em 2000, e 44\%, em 2008, e na faixa entre 1,01 e 1,5 sm ficou entre 52,94\%, em 2000, e 48\%, em 2008. No município de Rio Quente os rendimentos médios ficaram concentrados em duas faixas principais no ano de 2008. Isto é, 39,40\% dos empregados receberam entre 1,51 e $2 \mathrm{sm}$ e $28,07 \%$ receberam entre 2,01 e $3 \mathrm{sm}$. Na ACT de transporte houve registros gerados apenas para o ano de 2008, onde os rendimentos se concentraram na faixa entre 1,51 e $2 \mathrm{sm}$, com $50 \%$ da mão de obra.

Em síntese, conforme mapa (Figura 03), percebeu-se que em de Alto Paraíso 89\% dos empregados ganharam, em 2008, entre 1,01 e $2 \mathrm{sm}$. O mesmo ocorreu em Pirenópolis e Caldas Novas (80\%); em Goiás (70\%); em Goiânia (63\%) e em Rio Quente (50\%). Aruanã representou, no mapa do MIDTUR, o município com trabalhadores formais com menor rendimento (60\% receberam, em 2008, até $1 \mathrm{sm}$ ), ao passo que Rio Quente representa o de maiores rendimentos (9\% receberam entre 5,01 e $15 \mathrm{sm}$ ), assim como mostra a Figura 03.

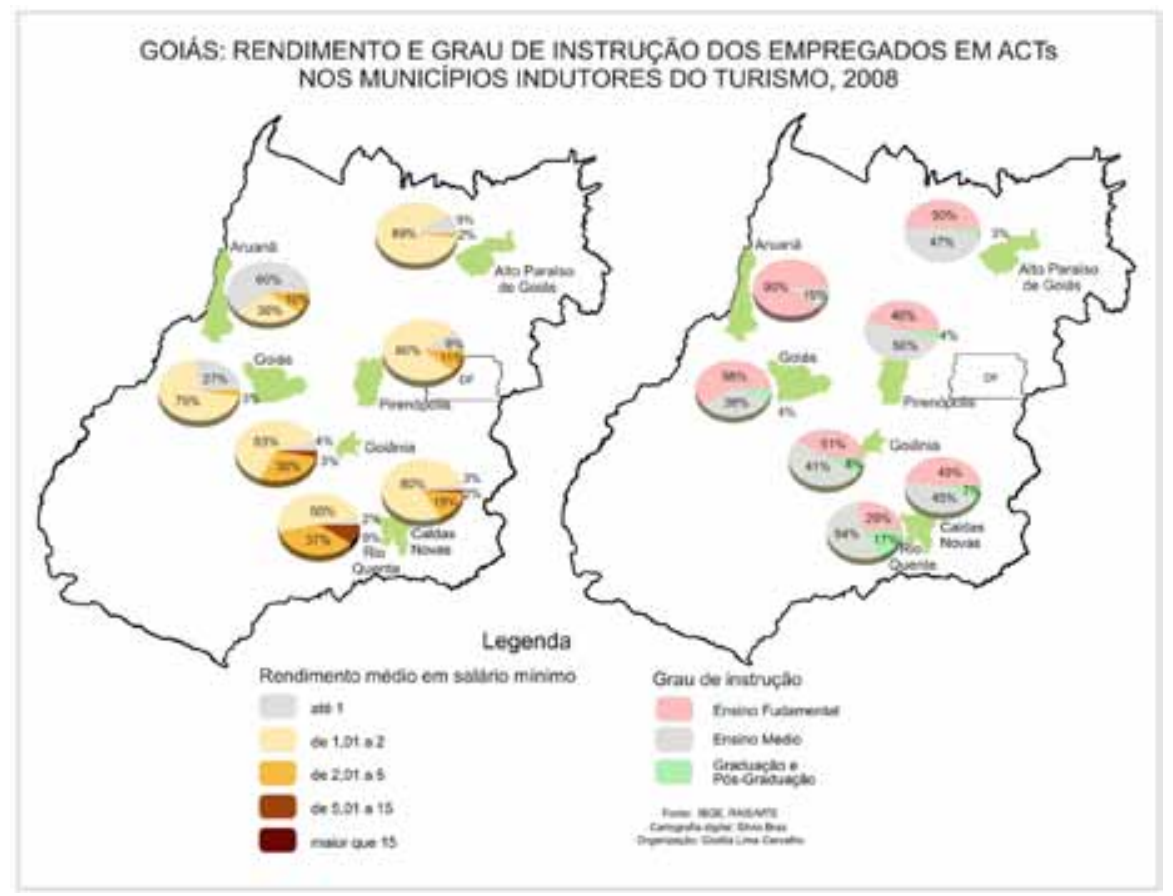

Figura 03 
Grau de instrução

Quanto ao grau de instrução dos trabalhadores de todas as ACTs dos municípios estudados, houve elevação no nível de escolaridade em geral de 2000 para 2008. Ou seja, em 2000, o destaque na formação dos trabalhadores foi para o Ensino Fundamental Completo e, em 2008, foi para a faixa dos que concluíram o Ensino Fundamental e o Ensino Médio Completos, sendo que destes, 33\% (10.421 trabalhadores) concluíram o Ensino Médio, 18\% (5.140) trabalhadores) estavam com o Ensino Médio Incompleto e 19\% (6.185 trabalhadores) com o Ensino Fundamental Completo (Figura 04).

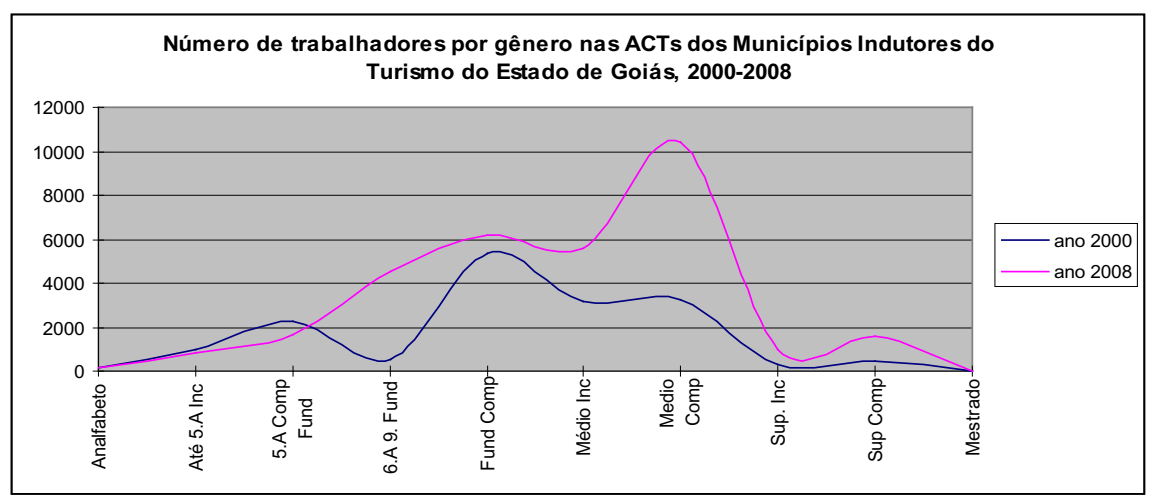

Figura 04

Fonte: RAIS/M.T.E

Em Alto Paraíso de Goiás a escolaridade concentrou-se entre o nível de $6^{\circ}$ a $9^{\circ}$ ano do Ensino Fundamental e o nível do Ensino Médio Completo. Notou-se que no município de Goiânia, na ACT de Agência de Viagens, o grau de instrução tem se elevado, pois em 2000 havia 42,95\% da mão de obra com ensino médio completo e em 2008 esse número saltou para $57,74 \%$. Teve um bom crescimento também o número de trabalhadores com Ensino Superior Completo, já que em 2000 havia somente 3,1\% de trabalhadores com esse grau de instrução e, em 2008, foram registrados 13,201\%. Nas ACTs de Alimentação e Alojamento o grande destaque se deu para o aumento nas contratações de mão de obra com Ensino Médio Completo que saltou de $16,71 \%$, em 2000, e para 36,20\%, em 2008. Na ACT de Alojamento esse número foi de $9 \%$, em 2000, mas subiu para $34,85 \%$, 
em 2008, representando o maior crescimento. Nas ACTs ligadas ao Transporte ocorreu a queda nas contratações de mão de obra com o $5^{\circ}$ ano do ensino fundamental completo e com $6^{\circ}$ a $9^{\circ}$ ano do ensino fundamental. Já na ACT de Cultura e Lazer cresceram as contratações de trabalhadores formais com ensino médio e superior completo. As contratações de mão de obra com ensino médio completo saltaram de 13,96\%, em 2000, para $28,45 \%$, em 2008, e com ensino superior completo saltou de 6,35\% para $16,19 \%$. Verificou-se, portanto, um aumento no nível da escolaridade no período estudado de forma geral. Já no município de Goiás o grau de instrução manteve-se entre $6^{\circ}$ e $9^{\circ}$ ano do ensino fundamental e o nível de ensino médio completo. Na ACT de Alojamento a presença de mão de obra com formação entre $6^{\circ}$ e $9^{\circ}$ ano do ensino fundamental teve aumento surpreendente, crescendo de $0 \%$, em 2000 , para $44,60 \%$, em 2008. No setor de Alimentação também houve esse crescimento, pois 17,65\% dos empregados tinham, em 2000, o Ensino Médio Incompleto chegando a 32\%, em 2008. Já no município de Pirenópolis o destaque foi para a presença de trabalhadores com ensino médio completo. Em 2000 as contratações nesta faixa corresponderam a 26,47\% e em 2008 elas saltaram para 38,80\%. No município de Rio Quente nas contratações da ACT de Alojamento, em 2008, 36,44\% da mão de obra empregada possuía o ensino médio completo e $9,82 \%$ possui ensino superior completo, um diferencial em todos os municípios.

A realidade do nível de instrução do pessoal ocupado no setor do turismo ainda precisa ser mudada, posto que há municípios com um alto nível de trabalhadores apenas com Ensino Fundamental, como é o caso de Aruanã (90\%); Goiás (58\%); Goiânia (51\%); Alto Paraíso (50\%); Caldas Novas (49\%) e Pirenópolis (46\%). Rio Quente representa o menor índice de empregados nesta faixa (29\%), conforme o mapa da figura 03.

\section{Gênero}

Com a análise dos dados sobre o gênero dos empregados do setor do turismo nos MIDTUR, percebeu-se que nas contratações predominaram o gênero masculino. Porém, foi possível notar que cresceu o número de contratadas do gênero feminino. Em 2000 foram empregadas 5.124 mil mulheres. Em 2008 este número saltou para 11.599 mil, ou seja, $6.475 \mathrm{mil}$ novas vagas de emprego ocupadas por mulheres. Todavia, empregou-se 
15.616 mil homens, em 2000, e 20.344 mil, em 2008, gerando, ao final do período, um saldo de 4.728 mil novos empregos para o gênero masculino (Figura 05).

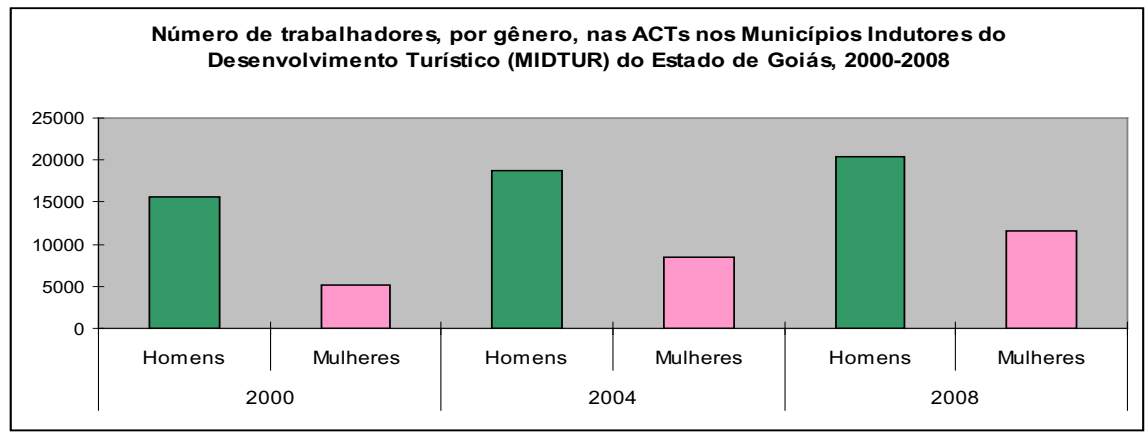

Figura 05

Fonte: RAIS/M.T.E

Vale ressaltar que o dado referente à inserção das mulheres cada vez maior no mercado de turismo não se dá somente no Estado de Goiás e nem no setor, mas está relacionada à mudança na estrutura da sociedade nas últimas décadas, levando a um estilo de vida essencialmente urbano, sendo o setor de serviços o mais aberto ao este público. E isto se ocorre porque, segundo Leone (2003, p. 200),

[...] o aumento da participação da mulher adulta na atividade econômica, sobretudo das esposas, elevou-se o número de famílias com mulher na força de trabalho, tornando-se cada vez mais evidente o fato de que a sobrevivência e/ou a manutenção do status quo das famílias dependem, mais e mais, do esforço coletivo de todos seus membros em idade para trabalhar, e a renda do trabalho da esposa tornou-se, essencial para a renda da maioria das famílias.

Este crescimento do número de mulheres se deu em alguns municípios do MIDTUR de forma ainda mais relevante, como foram os casos de Alto Paraíso, Goiás e Pirenópolis, onde registrou-se, ao longo do período, um número maior de mulheres que de homens empregados no setor. Nos demais municípios, sempre houve prevalência do gênero masculino em praticamente todo período (Figura 06). 


\begin{tabular}{|l|r|r|r|r|r|r|}
\hline \multicolumn{7}{|c|}{$\begin{array}{c}\text { Número de trabalhadores, por gênero, nas ACTs dos Municípios Indutores } \\
\text { do Turismo do Estado de Goiás, 2000-2008. }\end{array}$} \\
\hline \multirow{2}{*}{ MIDTUR } & \multicolumn{2}{|c|}{2000} & \multicolumn{2}{c|}{ 2004 } & \multicolumn{2}{c|}{2008} \\
\cline { 2 - 7 } & Homens & Mulheres & Homens & Mulheres & Homens & Mulheres \\
\hline Alto Paraíso & 16 & 18 & 64 & 98 & 64 & 101 \\
\hline Aruanã & 3 & 7 & 16 & 7 & 3 & 7 \\
\hline Caldas Novas & 344 & 152 & 1.291 & 785 & 1.706 & 1.182 \\
\hline Goiânia & 15.131 & 4.890 & 16.798 & 7.165 & 17.537 & 9.612 \\
\hline Goiás & 72 & 23 & 126 & 141 & 61 & 80 \\
\hline Pirenópolis & 37 & 27 & 0 & 0 & 170 & 189 \\
\hline Rio Ouente & 13 & 7 & 603 & 255 & 803 & 428 \\
\hline Total & 15.616 & 5.124 & 18.834 & 8.451 & 20.344 & 11.599 \\
\hline
\end{tabular}

Figura 06

Fonte: RAIS/M.T.E

Considerações finais

Com esse estudo foi possível verificar alguns impactos no setor de turismo tais como: um crescimento nos empregos formais nos municípios turísticos do Estado de Goiás que, de 2000 para 2004, registrou-se um crescimento de 41,31\% nos contratos e, de 2004 para 2008, apesar de bem menos significativo, verificou-se um crescimento de $8,68 \%$. Esse dado revela uma expansão do setor na economia goiana, a despeito de não terem sido averiguados aqui os índices de emprego informal que, segundo o IPEA, cresce numa proporção de 2 empregos informais para 1 formal. Notou-se também a presença cada vez maior da força de trabalho feminina que tem, em alguns municípios, superado a masculina. Ademais o setor vem se diversificando em termos de idade e elevando a escolaridade dos seus empregados. Entretanto, em termos salariais, a maioria dos empregados recebeu pagamentos, em 2008, na faixa entre 1,01 e 1,5 sm, ocorrendo ainda registros daqueles que receberam abaixo de $1 \mathrm{sm}$ em todos os municípios turísticos. No entanto, Rio Quente é o município que melhor remunera seus empregados: $37 \%$ deles receberam, em 2008, entre 2,01 e $5 \mathrm{sm}$ e $9 \%$ entre 5,01 e $15 \mathrm{sm}$. Soma-se a isso, o fato de também valorizar a formação: $17 \%$ dos empregados, em 2008, tinham o ensino superior completo e alguns até a pós-graduação. Realidade pouco comum 
nos demais municípios indutores (Goiânia apresentou apenas 8\% nesse nível e Caldas Novas 7\%).

Em termos contratuais, o setor de Alimentação posicionou-se como o mais sólido no município de Goiânia e o de Hospedagem nos municípios de Caldas Novas, Rio Quente e Pirenópolis. Aqui não se verificou os índices de realocação de empregados no setor, mas sabendo da alta rotatividade que há, sobretudo, nas pequenas empresas do setor de alimentação e hospedagem, é vital que se pense na questão como um problema que compromete a vida do trabalhador e reflete a má qualidade na prestação de serviços e, por este aspecto, merece ser considerado na proposição de políticas de geração de empregos, conforme ressaltam Amorim e et al. ( 2006) ${ }^{6}$.

O Ministério do Turismo e a Embratur, no Plano Nacional de Turismo (2007-2010, p. 40), fez um diagnóstico da realidade turística brasileira em relação à gestão e ao planejamento. Há um reforço, neste plano, em quesitos que impedem de "alcançar a excelência no atendimento e na prestação de serviços". Dentre eles está a mão de obra empregada no turismo que "apresenta baixa escolaridade, baixa remuneração e alta rotatividade”. Estes apontamentos são reforçados aqui nesta pesquisa e espera-se que ela contribua para a formação de um banco de dados que não só caracterize a situação atual do turismo no Estado de Goiás, mas que seja um reforço teórico-metodológico para a coleta de informações sobre as ACTs no Brasil e em suas escalas estaduais, servindo de apoio para as políticas territoriais e ações do setor privado. Isto é válido porque sabemos que o panorama do turismo se desenvolverá dependendo das opções feitas pelos gestores públicos e privados que atuam diretamente no setor. No entanto, a tomada de decisões deve ocorrer amparada, cada vez mais, em referenciais concretos da realidade.

\section{Notas}

1 Este artigo é parte dos resultados finais da pesquisa intitulada "Caracterização e análise do perfil da mão de obra ocupada no turismo do Estado de Goiás, a partir de 2000" coordenada pela autora, realizada no Instituto Federal de Goiás (IFG) e financiada pela Fundação de Amparo à Pesquisa do Estado de Goiás (FAPEG).

2 A respeito da qualidade dos dados da RAIS, a partir de 1990, pode se afirmar que ela tem apresentado melhoras evidentes (AMORIM e et al, 2006). A partir de 2000, segundo a Embratur, é possível assegurar melhor a padronização e 
a confiabilidade das informações, uma vez que já alertou sobre a dificuldade de uniformizar os dados do turismo, haja vista que o nível de confiabilidade dos índices para todo o Brasil ainda é baixo, sobretudo se considerada a escala municipal.

3 Domicílio de uso ocasional, segundo o IBGE (2010), é o domicílio particular permanente que na data de referência servia ocasionalmente de moradia. $\mathrm{Ou}$ seja, compõem o grupo desses domicílios aqueles usados para descanso de fins de semana, férias ou outro fim, mesmo que, na data de referência, seus ocupantes ocasionais estivessem presentes.

4 A região Turística da Reserva da Biosfera Goyaz abrange o nordeste do Estado de Goiás. Atualmente 26 municípios fazem parte desse território, e foi reconhecido pela UNESCO como Patrimônio Natural da Humanidade (UNB/ CET).

5 O número de empregados, com contrato de trabalho, com base na RAIS/M.T.E, entre 2000 e 2008, no setor do turismo manteve-se estável, em torno de $7 \%$ do total de empregados classificados na CNAE.

6 O setor de serviços no Brasil, no qual o turismo está inserido, apresenta as maiores taxas de realocação de empregos (cerca de $30 \%$ ), sendo que o setor possui maior peso no total de empregos, superando até mesmo a indústria (AMORIM e et al., 2006). Esta taxa de realocação de empregos é alta para os padrões internacionais e parece advir da maior destruição de empregos de firmas existentes e da maior criação de empregos pelo nascimento de novas firmas. Isto reflete um processo de maior dinamicidade da oferta e extinção de empregos na economia atrelada a uma maior vulnerabilidade para os empregados notada em uma alta rotatividade que não é interessante para a economia e sociedade. No turismo, esses índices se expressam melhor nos setores de Hospedagem e Restaurantes e menos no de transportes, conforme destacado por Amorim e et al ( 2006).

\section{Referências}

AMORIM, Brunu M. F. e et al. Criação, destruição e realocação de postos de trabalho por setores. In: CORSEUIL, C. H. \& SERVO, L. M. S. (Orgs.). Criação, destruição e realocação de empregos no Brasil. Brasília: IPEA, 2006.

BRASIL. INSTITUTO BRASILEIRO DE GEOGRAFIA E ESTATÍSTICA - IBGE. Estimativas da mão de obra formal ocupada em atividades características do turismo, para 20 municípios indutores do turismo, dezembro de 2002 e setembro de 2008. Disponível em: IPEA, nov. 2008. Disponível em: http://www.ipea.gov.br/

. Censo Demográfico 2011. Rio de Janeiro: IBGE, 2011. Disponível em: http:// www.ibge.gov.br/

. Guia do censo 210 para Jornalista. Glossário. Disponível em: http://www. ibge.gov.br/home/presidencia/noticias/guia_do_censo_2010_glossario.php

. INSTITUTO DE PESQUISA ECONÔMICA APLICADA - IPEA. Sistema de informações sobre o mercado de trabalho no setor turismo no Brasil: proposta 
metodológica para a produção de indicadores correntes sobre o mercado de trabalho no setor turismo por meio de fontes secundárias de cobertura nacional, Brasília, 2004. Disponível em: http://www.ipea.gov.br/.

. MINISTÉRIO DO TRABALHO E EMPREGO (M.T.E). Relação Anual de Informações Sociais (RAIS). Brasília. Disponível em: http://portal.M.T.E.gov.br/ portal-mte/.

CALA, Antonia Sáez. La actividad turística: conceptos, clasificaciones y fuentes de información. CALA \& et. al. (Orgs.). Estructura económica del turismo. Madri: Síntesis, 2006.

. MINISTÉRIO DO TURISMO/EMBRATUR. Plano Nacional de Turismo: uma viagem de inclusão, 2007-2010. Brasília, 2007. Disponível em: http://www. turismo.gov.br/turismo/o_ministerio/plano_nacional/.

GOIÁS. GOIAS TURISMO. AGÊNCIA ESTADUAL DE TURISMO. Plano Estadual de Turismo. Disponível em: http://www.goiasturismo.go.gov.br/. Acessado em $15 / 05 / 2011$.

LEONE, Eugênica T. O trabalho da mulher nas regiões metropolitanas brasileiras. In: PRONI, M. W. \& HENRIQUE, W. (Org.). Trabalho, Mercado e Sociedade: o Brasil nos anos 90. São Paulo: Unesp, 2003.

UNIVERSIDADE DE BRASÍLIA - UNB. CENTRO DE EXCELÊNCIA EM TURISMO - CET. Fórum Regional de Turismo da Reserva da Biosfera Goyaz. Disponível em: http://cet.unb.br/portal/attachments/article/1654/Apresentacao_Estrada.pdf

Gisélia Lima Carvalho - Mestrado em Geografia pela Universidade Federal de Goiás. Professora da Coordenação de Turismo e Hotelaria do Instituto Federal de Educação, Ciência e Tecnologia de Goiás.

Recebido para publicação em março de 2011. Aceito para publicação em maio de 2011. 